\title{
Nuclear Structure
}

National Cancer Institute

\section{Source}

National Cancer Institute. Nuclear Structure. NCI Thesaurus. Code C13446.

Any structures that are enclosed within nucleus are considered nuclear structure,

including any macromolecular structures. $(\mathrm{NCl})$ 